\title{
Benign Mediastinal Neoplasm
}

National Cancer Institute

\section{Source}

National Cancer Institute. Benign Mediastinal Neoplasm. NCI Thesaurus. Code C3604.

A non-metastasizing neoplasm that arises from the mediastinum. Representative examples include lipoma, leiomyoma, and schwannoma. 